\title{
Revealing the organic dye and mordant composition of Paracas textiles by a combined analytical approach
}

Francesca Sabatini ${ }^{1}$, Martina Bacigalupo ${ }^{1}$, Ilaria Degano ${ }^{1 *} \mathbb{D}$, Anna Javér ${ }^{2}$ and Marei Hacke ${ }^{3^{*}}$

\begin{abstract}
The object of this study is a wide selection of dyed cotton and camelid samples from an important collection of 2000-year-old Paracas textiles, now at the Museo Nacional de Arqueología, Antropología e Historia del Perú (MNAAHP; Lima; Peru) and at the National Museum of World Culture (NMWC; Gothenburg; Sweden). The threads, chosen as representative of the whole palette, were selected from eighteen different textiles. A combined spectroscopic and spectrometric analytical approach was selected to characterize the organic and inorganic composition of this wide set of samples. In particular, technical photography was used to gain a general overview of the samples, X-ray fluorescence (XRF) was employed for identifying the mordants and mapping the elemental distribution in the threads, while liquid chromatography coupled with diode array detector and with high-resolution mass spectrometry (HPLC-DAD, HPLC-HRMS) were used for characterizing organic dye composition. This study provides fundamental information on the mordants or other inorganic auxiliaries used in the dyeing processes, rarely investigated up to now, and to the varieties of vegetal sources employed in Paracas textiles. The widening of the Andean dyestuff database is highly important not only to acquire knowledge on Paracas culture, but also to ease the dye characterization of archaeological textiles from the Peruvian region and South American area in general.
\end{abstract}

Keywords: Paracas textiles, Organic dyes, Mordants, HPLC-HRMS, XRF mapping

\section{Introduction}

The Paracas civilization spread over six valleys along the Pacific coast in southern Peru, between 900 BC and $150 \mathrm{AD}$ [1]. This pre-Hispanic culture is renowned for the funerary bundles constituted by multi-layer textiles, garments and several other objects recovered from the necropolis. The fine Paracas textiles are embroidered with distinctive characters and imagery in elaborate patterns characterized by strong colours in numerous hues. Most often the fabric ground weaves are made of cotton while the embroidery yarns are of camelid fibres.

\footnotetext{
*Correspondence: marei.hacke@raa.se

1 Department of Chemistry and Industrial Chemistry, University of Pisa, Via

Moruzzi, 13, 56126 Pisa, Italy

${ }^{3}$ Heritage Laboratory, Swedish National Heritage Board, Box 1114, 621

22 Visby, Sweden

Full list of author information is available at the end of the article
}

The vegetal sources, recipes and techniques applied for dyeing the yarns are mostly unknown due to the lack of detailed historical written documents and the paucity of scientific studies.

The 2000-year-old Paracas textiles from which the threads are sampled were excavated and brought to Gothenburg in Sweden during the 1930s. The 89 large textiles constituted an important museum collection in Gothenburg for almost 90 years. After the exhibition "A Stolen World" (NMWC; 2008-2009), Peru asked for repatriation of the textiles. The textiles were repatriated to Peru in three clusters: 2014, 2017, and the last planned for 2021 [2].

This study builds on previous work in which mordants were investigated in situ by X-ray fluorescence (XRF) mapping of small areas of textile fragments and fibre strength was assessed by compression testing of thread samples [3]. Measurements of $\mathrm{pH}$ and analyses by

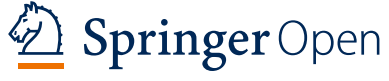

(c) The Author(s) 2020. This article is licensed under a Creative Commons Attribution 4.0 International License, which permits use, sharing adaptation, distribution and reproduction in any medium or format, as long as you give appropriate credit to the original author(s) and the source, provide a link to the Creative Commons licence, and indicate if changes were made. The images or other third party material in this article are included in the article's Creative Commons licence, unless indicated otherwise in a credit line to the material. If material is not included in the article's Creative Commons licence and your intended use is not permitted by statutory regulation or exceeds the permitted use, you will need to obtain permission directly from the copyright holder. To view a copy of this licence, visit http://creativeco mmons.org/licenses/by/4.0/. The Creative Commons Public Domain Dedication waiver (http://creativecommons.org/publicdomain/ zero/1.0/) applies to the data made available in this article, unless otherwise stated in a credit line to the data. 
scanning electron microscopy-energy dispersive X-ray spectroscopy (SEM-EDX) were also carried out at the time but proved less informative than the other techniques. The aims of the previous study included an investigation of the condition of textiles that had undergone a deacidification treatment with ammonia in the 1990s. Notable differences appeared to be related to the colours of the threads rather than their storage conditions or deacidification treatment. It was subsequently decided to further investigate this through identification of the organic colorant and inorganic components such as mordants or other dyeing auxiliaries. Additional threads were also subjected to compression testing in order to widen the dataset for condition assessment.

Relatively few studies deal with the characterisation of the molecular composition of South American reference dyeing materials and pre-Columbian archaeological textiles [4]. The first papers on this topic were based on the identification of organic dyes by UV-Vis spectroscopy [5-12]. Other spectroscopic techniques were also applied for dyes detection such as fibre optics reflectance spectroscopy (FORS) [13], microspectrofluorimetry [14, 15] and surface enhanced Raman spectroscopy (SERS) [14, 16], while infrared spectroscopy (IR) [7] was rarely used due to the dominant absorption of the textile matrix in the spectra. Liquid chromatography coupled with spectroscopic detectors [13,17-21] was frequently successful in identifying the different main components used in the dyeing processes, but the coupling with mass spectrometry (MS) and in particular with high resolution mass spectrometry (HRMS) lead to the exhaustive characterization of the single compounds and thus to fully characterise raw dye materials and archaeological sample extracts $[18,20]$. One of the main issues related to the application of liquid chromatography is the optimization of sample treatment: since the range of chemical classes exploited as colouring materials is extremely broad, the molecular markers of each dye differ in terms of solubility and reactivity in acidic and alkaline media. Thus, choosing a stronger or milder method results in a different profile of the extracted compounds. In particular, the application of strong conditions, such as those employed in the first studies on Peruvian archaeological textiles [21], lead to the breaking of glycosidic bond, a partial decarboxylation or dehydration of molecular markers, and the esterification of phenolcarboxylic compounds [22]. More recently, mild methods were developed for retaining the glycosidic components, which yield much of the information useful for the identification of a particular plant or other dyestuff used to colour a textile [23]. New trends in rapid and efficient ambient ionization mass spectrometric techniques, such as direct analysis in real time (DART) [17, 24], paper spray [17] and flowprobe [25] (all coupled with
HRMS), are also successfully being applied to detect dyes in Andean textiles.

Compared with dye analyses, few attempts have been made, prior to this study, to identify dyestuff mordants or inorganic dye auxiliaries in pre-Columbian textiles. Studies known to the authors were all performed by XRF or SEM-EDX $[3,11,14]$.

In this paper an analytical approach based on technical photography, XRF and liquid chromatography coupled with diode array detector and high-resolution mass spectrometry (HPLC-DAD, HPLC-HRMS) was employed to characterize both the inorganic components and the organic dye sources used in a wide collection of Paracas textiles. An attempt to correlate the dyeing source and the inorganic components to the actual conservation state of the textile threads was performed, and all results are discussed in detail.

\section{Methods}

\section{Historical samples}

This study includes samples from a previous work, where 34 samples from 12 textiles were investigated [3]. For the present study 14 additional samples were collected from six other textiles and from two of the previously sampled textiles. Figure 1 displays a selection of the textiles analysed. The thread samples were ca. $10 \mathrm{~mm}$ long and between 0.1 and $2.0 \mathrm{mg}$ in weight. $1.0 \mathrm{~mm}$ sections of each of the threads were subjected to the same compression test as mentioned previously [3]. The same threads, including those left from the previous study, were documented by technical photography (38 threads), analysed by XRF mapping (34 threads), HPLC-DAD and HPLCHRMS (27 threads).

The colour, the fabric, the object from which they were sampled, and the techniques used for analysing each sample are reported in Additional file 1: Table S1.

\section{Reference materials}

The following materials belonging to the collection of plants and dyed yarns of SCIBEC group (Department of Chemistry and Industrial Chemistry, University of Pisa) were specifically employed for this project as references for the chromatographic analyses. Cosmos sulphureus petals were kindly provided by Dr. David Buti, who purchased the seeds from "La Semeria" (Aulla (MS), Italy); Cosmos sulphureus is known as a dye source in Mexico and South America [26, 27].

Wool and alpaca threads dyed with Relbunium hypocarpium, Relbunium ciliatum, Dactylopius coccus, Baccharis floribunda, Hypericum larcifolium and Kageneckia lanceolata were sampled from a notebook containing recipes and materials collected in Peru and prepared by Kay Antúnez de Mayolo, a botanist who 

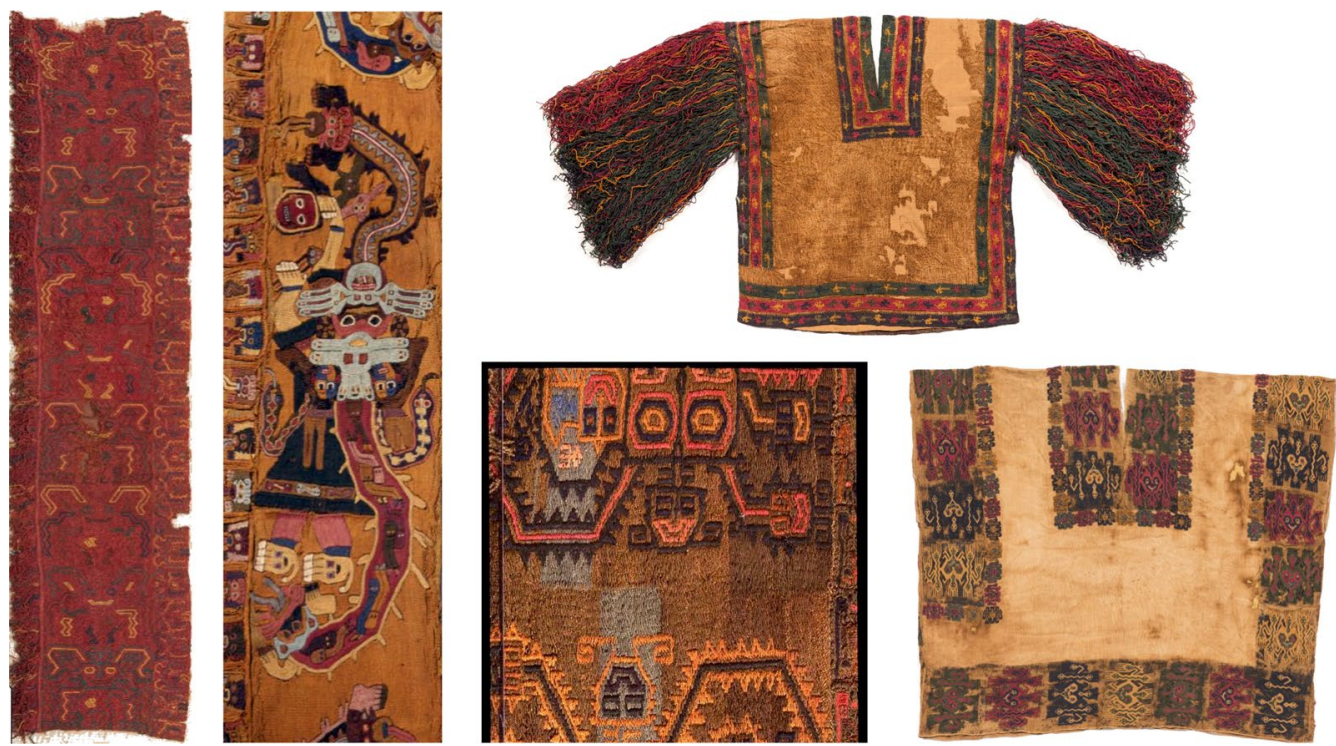

Fig. 1 A selection of the textiles analysed. From left to the right: fragment of a red border 1932.16.0165; detail of a yellow border 1935.32.0198; detail of a green border 1935.32.0173, the tunic with heart shaped faces 1935.32.0122b and the hummingbird tunic with fringes 1935.32.0085/ RT-043457 (top) in the Gothenburg Collection. Photo: The National Museums of World Culture, Sweden (CC-BY).

was working as a field assistant for Mr Saltzman [17, 28, 29], and now preserved at UCLA (Los Angeles, USA). The data obtained for the characterisation of these wool and alpaca threads are reported in previous studies $[17$, $18]$.

All reference raw materials and dyed yarns (including Cosmos petals) were extracted and analysed with the same method as the archaeological samples.

\section{Technical photography}

For technical photography the samples were laid out on a filter paper and covered with silk netting to keep the thread samples in place. A modified Nikon D5500 camera without its IR filter was used with a Nikon AF NIKKOR $50 \mathrm{~mm}$ 1:1.4 D Ø52 lens. The following light sources were used: UV $<400 \mathrm{~nm}$ (UVA 366, purchased from G. Engelbrecht $\mathrm{GmbH}$ ); visible spectrum 425-750 nm LED light adjustable between 3200 and $5500 \mathrm{~K}$ (Amaran AL-528 C, from Aputure); and IR $>750 \mathrm{~nm}$ (LED light Synergy 21 from Allnet), in conjunction with the following pass filters from Schneider / Kreuznach: UV Pass (- $400 \mathrm{~nm} \sim 85 \%, 450-685 \mathrm{~nm}$ 0\%, $740 \mathrm{~nm} \mathrm{50 \% ,} \mathrm{B} \mathrm{+W} \mathrm{403);} \mathrm{UV/IR} \mathrm{Cut}(-<375 \mathrm{~nm}$ $0 \%, 400-675>90 \%,>700 \mathrm{~nm} \mathrm{0 \% ,B+W} \mathrm{486);} \mathrm{NIR/}$

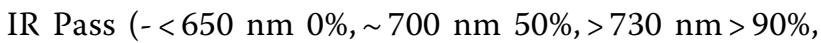
$\mathrm{B}+\mathrm{W}$ 092); IR Pass $(-<800 \mathrm{~nm}<1 \%, \sim 830 \mathrm{~nm}$ $50 \%,>900 \mathrm{~nm}>88 \%, \mathrm{~B}+\mathrm{W} 093)$. The theory and application of technical photography is explained in the literature [30].

\section{HPLC-DAD and HPLC-HRMS}

For high performance liquid chromatography with diode array detection (HPLC-DAD) analyses the system consisted of a PU-2089 quaternary pump equipped with a degasser, an AS-950 autosampler, and an MD-2010 spectrophotometric diode array detector (all modules are Jasco International Co., Japan). The software used for the analysis was ChromNav (Jasco International). The diode array detector (DAD) acquisition was performed in the range of 200-650 $\mathrm{nm}$ every $0.8 \mathrm{~s}$ with $4 \mathrm{~nm}$ resolution.

For high performance liquid chromatography interfaced through an electrospray ion source to the quadrupole-time of flight mass spectrometric detection (HPLC-ESI-Q-ToF) analysis the system consisted of a HPLC 1200 Infinity, coupled with a quadrupole-time of flight mass spectrometer Infinity Q-ToF 6530 detector by a Jet Stream ESI interface (Agilent Technologies). The ESI conditions were: drying and sheath gas $\mathrm{N}_{2}$, purity $>98 \%$, temperature $350{ }^{\circ} \mathrm{C}$, flow $10 \mathrm{~L} / \mathrm{min}$ and temperature $375{ }^{\circ} \mathrm{C}$, flow $11 \mathrm{~L} / \mathrm{min}$, respectively; capillary voltage $4.5 \mathrm{kV}$; nebulizer gas pressure 35 psi. The fragmentor voltage was $175 \mathrm{~V}$; nozzle, skimmer and octapole RF voltages were set at $1000 \mathrm{~V}, 65 \mathrm{~V}$ and $750 \mathrm{~V}$, respectively. The high-resolution mass spectrometric (MS) and tandem mass spectrometric (MS/ MS) acquisition range was set from 100 to $1000 \mathrm{~m} / \mathrm{z}$ in negative and positive mode, with acquisition rate $1.04 \mathrm{spectra} / \mathrm{s}$. All samples were investigated in negative mode, while positive acquisition was undertaken for samples MNAAHP-008 and PAR-037 only. For the 
MS/MS experiments, $30 \mathrm{~V}$ were applied in the collision cell to obtain CID fragmentation (collision gas $\mathrm{N}_{2}$, purity $99.999 \%$ ). The FWHM (full width half maximum) of quadrupole mass bandpass used during MS/ MS precursor isolation was $4 \mathrm{~m} / \mathrm{z}$. The Agilent tuning mix HP0321 was used to calibrate the mass axis daily.

The eluents used for the HPLC-DAD analyses were water and acetonitrile (ACN), both HPLC grade (Sigma Aldrich, USA), while the eluents for HPLC-ESI-Q-ToF analyses were water and acetonitrile, both LC-MS grade (Sigma-Aldrich, USA). All eluents were added with $0.1 \% \mathrm{v} / \mathrm{v}$ formic acid (FA; $98 \%$ purity, J.T. Baker, USA).

For both the systems, the chromatographic separation was performed on an analytical reversed-phase column Poroshell $120 \mathrm{EC}-\mathrm{C} 18(3.0 \times 75 \mathrm{~mm}$, particle size $2.7 \mu \mathrm{m})$ with a Zorbax pre-column $(4.6 \times 12.5 \mathrm{~mm}$, particle size $5 \mu \mathrm{m}$ ), both Agilent Technologies. The flow rate was $0.4 \mathrm{~mL} / \mathrm{min}$ and the program was: $15 \% \mathrm{~B}(0.1 \%$ FA in $\mathrm{ACN}$ ) for $2.6 \mathrm{~min}$, then to $50 \% \mathrm{~B}$ in $13.0 \mathrm{~min}$, to $70 \% \mathrm{~B}$ in $5.2 \mathrm{~min}$, to $100 \% \mathrm{~B}$ in $0.5 \mathrm{~min}$ and then held for $6.7 \mathrm{~min}$. Re-equilibration took $11 \mathrm{~min}$. During the separation, the column was kept at $30^{\circ} \mathrm{C}$.

All the samples were subjected to a mild pre-treatment consisting in: adding of $300 \mu \mathrm{L}$ of $0.1 \%$ ethylenediaminetetraacetic acid disodium salt $\left(\mathrm{Na}_{2} \mathrm{EDTA}\right.$; Fluka, USA) in water and dimethyl formamide (DMF; 99.8\% purity, J.T. Baker, USA) solution $\left(\mathrm{Na}_{2}\right.$ EDTA in $\mathrm{H}_{2} \mathrm{O} /$ DMF $\left.(1: 1, \mathrm{v} / \mathrm{v})\right)$ to the sample in a closed glass vial, extracting in ultrasonic bath at $60{ }^{\circ} \mathrm{C}$ for $1 \mathrm{~h}$, filtering with PTFE filters $(0.45 \mu \mathrm{m}$ pore size), injecting 20 $\mu \mathrm{L}$ and $4-20 \mu \mathrm{L}$ of the extract in the HPLC-DAD and HPLC-ESI-Q-ToF, respectively.

The detailed description of the HPLC principles and terminology for a better understanding of the text is available in the literature $[22,31]$.

\section{XRF mapping}

For XRF mapping the thread samples were mounted on filter paper that was suspended over a hole in a plastic foam and covered with silk netting to keep the fibres in place. The entire area with 34 laid out threads was then mapped with a Bruker micro-XRF Artax 800 using a molybdenum X-ray tube at $50 \mathrm{kV}$ and $600 \mu \mathrm{A}$ and a poly capillary lens yielding a spot size of $60-70 \mu \mathrm{m}$. The map was collected in air as it was not possible to fix the samples in place to withstand the pressure from helium flushing. The scan live time per spot was $5 \mathrm{~s}$, number of measurements 20,155, spot distance $0.18 \mathrm{~mm}$, scan area $26 \mathrm{~mm} \times 25 \mathrm{~mm}$ and total scan time 61:35 h.

An additional map of many of the same thread samples had been collected previously but at lower resolution and on a different mounting material-polystyrene, which gave a lower Bremsstrahlung background in the XRF spectra compared to the filter paper background. Mounting the samples on polystyrene was problematic as the static charge on the plastic could cause the fibres to move. The results of the two maps are comparable, with the same elements present at predominantly the same relative intensities. This confirmed that the technique is valid for the relative or semi-quantitative assessment of inorganic components in textiles. The accumulated spectra from both maps show which elements were detected over the entire areas (Fig. 2). All spectra contain peaks for molybdenum (from the incident X-ray source) and argon (instrument specific). X-ray fluorescence response can be very different between different elements, meaning that peak heights or net peak area counts cannot be used to judge the quantities of elements within one spectrum, but semi-quantitative information can be gained from area maps, assuming that the sample matrix (i.e. thickness and density of the threads) is the same across all measuring points.

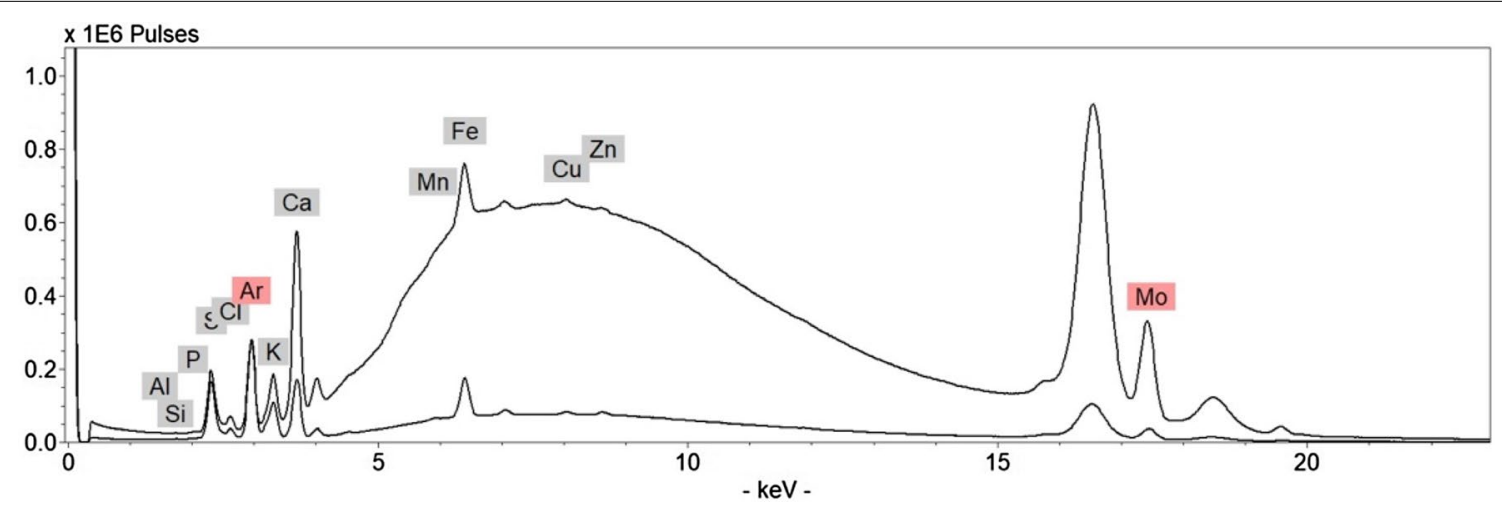

Fig. 2 Accumulated spectrum from 20,155 points on $\mu$ XRF map (upper line, threads mounted on filter paper) and accumulated spectrum from 5396 points on $\mu$ XRF map (lower line, threads mounted on polystyrene) 
Results from the additional map are provided in Additional file 1: Table S2 but are not further discussed in the main text.

\section{Compression tests}

Samples were supported on glass microscope slides. $1 \mathrm{~mm}$ sections were cut from each thread sample, ensuring that the yarn twist and ply were not altered. The sample was then covered with a $2 \times 2 \mathrm{~cm}$ microscope slide cover glass and a $200 \mathrm{~g}$ weight. Before and after compression, images were taken with a stereomicroscope. The sample behaviour under compression was noted and used to subdivide the samples into three categories of stability: flexible/strong; fraying/weak and very fragile.

\section{Results and discussion}

The results are organised showing first the results of the technical photography, then discussing the organic dyes, followed by XRF mapping and compression testing in relation to the identified dyes. The organic dyes section is subdivided according to the colours of the threads. A complete summary of all the results is reported in Table 1.

\section{Technical photography}

The technical photography revealed some UV fluorescence effects. Figure 3 shows the visible light photograph and the UV induced visible fluorescence image of all the samples analysed. The white camelid samples (PAR-011, MNAAHP-006a and MNAAHP-003) are the only ones showing UV induced visible fluorescence. All three were shown to be undyed by chromatographic analysis (see Sect. "White threads" and Table 1). The natural fluorescence of wool is a known phenomenon [32]. None of the other images collected during technical photography showed recognisable photochemical effects.

\section{Analysis of the organic dyes White threads}

The white threads (samples MNAAHP-003, MNAAHP006a, PAR-011 and PAR-026) were analysed by HPLCDAD and the chromatograms extracted at all the channels in which red, yellow, green, blue and dark dyes may absorb (450 nm, max abs 300-400 nm and max abs 550-650 nm) are shown in Additional file 1: Figure S1ac. All chromatograms (Additional file 1: Figure S1a-c) are featureless (no peaks) allowing us to conclude that the white cotton (sample PAR-026) and camelid threads (samples MNAAHP-003, MNAAHP-006a and PAR-011) are undyed. HPLC-HRMS confirmed the lack of dyes above detection limit in all the white samples.

\section{Red threads}

The HPLC-DAD chromatograms of all the red threads of the set (samples MNAAHP-001, MNAAHP-007, MNAAHP-009, PAR-007, PAR-009, PAR-019, PAR-021 and PAR-025), extracted at $450 \mathrm{~nm}$ to enhance the $\mathrm{S} / \mathrm{N}$ ratio for the peaks due to anthraquinone red compounds, are reported in Fig. 4a.

All the HPLC-DAD chromatograms (Fig. 4a) show the same qualitative profile despite the different peak intensities given by the different absolute concentration of the extracts. Pseudopurpurin (14.9 min), munjistin $(15.3 \mathrm{~min})$ and purpurin $(20.5 \mathrm{~min})$ were identified thanks to the comparison with reference materials, analytical standards, and based on UV-Vis spectra reported in the literature [33]. HRMS allowed us to unequivocally identify and confirm the presence of several anthraquinones thanks both to the exact mass values acquisition (as deprotonated molecule, $[\mathrm{M}-\mathrm{H}]^{-}$) and the comparison with the tandem mass spectra of known compounds $[17,33]$ : pseudopurpurin $(m / z=299.019)$, munjistin $(m / z=283.002)$, lucidin $(m / z=269.043)$, xanthopurpu$\operatorname{rin}(\mathrm{m} / z=239.031)$, purpurin $(\mathrm{m} / z=255.029)$, rubiadin $(m / z=253.051)$ and nordamnacanhtal $(m / z=267.035$; in traces). A still unidentified peak, detected at $11.5 \mathrm{~min}$, featured both the UV-Vis and product-ion mass spectrum typical of anthraquinones (Additional file 1: Figure S2a-c). The HPLC-ESI-Q-ToF extracted ion chromatogram (EIC) of sample MNAAHP-009 is shown as representative of the composition of all the read threads (Fig. 4b).

The reported composition suggests that the dye source employed belonged to a Relbunium vegetal species [34]. The comparison of the obtained profiles with those of some Relbunium species employed for dyeing alpaca and sheep fibres from the Saltzman collection (Relbunium hypocarpium, Relbunium ciliatum, Relbuniumunknown species), already characterized in the literature $[17,18,24]$ and available as reference materials, allowed us to conclude that the most plausible vegetal source for the three samples is Relbunium hypocarpium. The small differences in composition could be due to the use of a mixture of distinct Relbunium species, different dyeing processes, or degradation of the textiles.

\section{Blue threads}

The HPLC-DAD profiles of the three blue threads of the collection (samples MNAAHP-004, MNAAHP-010 and PAR-024) feature two peaks ascribable to indigoid compounds: indigotin $(20.4 \mathrm{~min})$ and indirubin 
Table 1 List of the Paracas threads analysed with their relative description, identified inorganic elements, molecular markers, and hypothesis on the possible dye sources

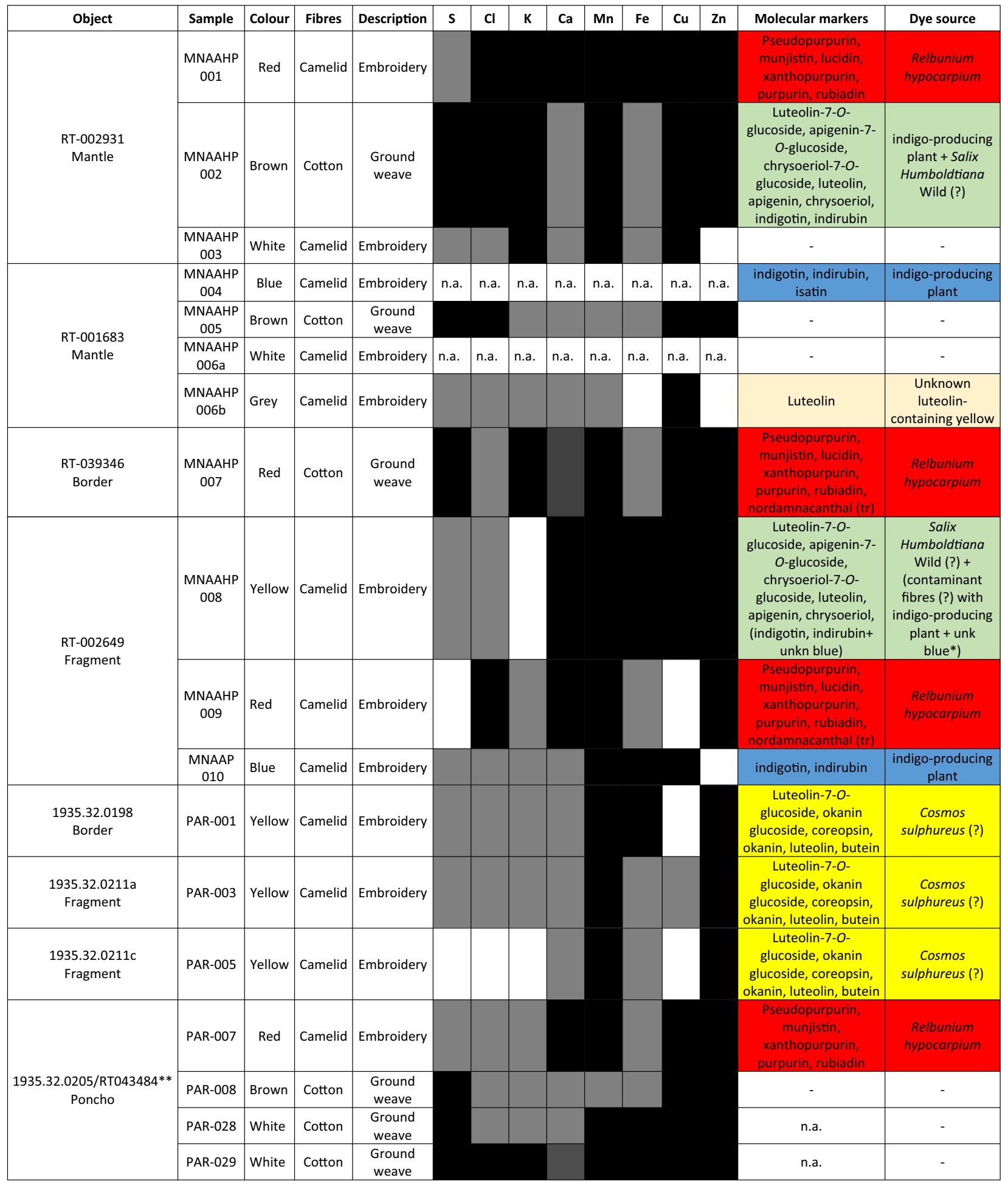


Table 1 (continued)

\begin{tabular}{|c|c|c|c|c|c|c|c|c|c|c|c|c|c|c|}
\hline \multirow{3}{*}{$\begin{array}{c}\text { 1935.32.0085/RT- } \\
043457^{* *} \\
\text { Tunic }\end{array}$} & PAR-009 & Red & Camelid & Embroidery & & & & & & & & & $\begin{array}{l}\text { Pseudopurpurin, } \\
\text { munjistin, } \\
\text { xanthopurpurin, } \\
\text { purpurin, rubiadin }\end{array}$ & $\begin{array}{l}\text { Relbunium } \\
\text { hypocarpium }\end{array}$ \\
\hline & PAR-026 & White & Cotton & $\begin{array}{l}\text { Ground } \\
\text { weave }\end{array}$ & & & & & & & & & n.a. & - \\
\hline & PAR-027 & White & Cotton & $\begin{array}{l}\text { Ground } \\
\text { weave }\end{array}$ & & & & & & & & & n.a. & - \\
\hline $\begin{array}{c}\text { 1935.32.0179/RT-038072* } \\
\text { Mantle }\end{array}$ & PAR-011 & White & Camelid & Embroidery & & & & & & & & & - & - \\
\hline \multirow[b]{2}{*}{$\begin{array}{c}\text { 1935.32.0190/RT-038073* } \\
\text { Mantle }\end{array}$} & PAR-019 & Red & Camelid & Embroidery & & & & & & & & & $\begin{array}{l}\text { Pseudopurpurin, } \\
\text { munjistin, } \\
\text { xanthopurpurin, } \\
\text { purpurin }\end{array}$ & $\begin{array}{l}\text { Relbunium } \\
\text { hypocarpium }\end{array}$ \\
\hline & PAR-020 & Black & Cotton & $\begin{array}{l}\text { Ground } \\
\text { weave }\end{array}$ & & & & & & & & & $\begin{array}{l}\text { Luteolin-7-O- } \\
\text { glucoside, apigenin-7- } \\
\text { O-glucoside, } \\
\text { chrysoeriol-7-O- } \\
\text { glucoside, luteolin, } \\
\text { apigenin, chrysoeriol, } \\
\text { indigotin, indirubin }\end{array}$ & $\begin{array}{l}\text { indigo-producing } \\
\text { plant + Salix } \\
\text { Humboldtiana } \\
\text { Wild (?) }\end{array}$ \\
\hline \multirow{3}{*}{$\begin{array}{c}\text { 1935.32.0188/RT-038074* } \\
\text { Poncho }\end{array}$} & PAR-021 & Red & Camelid & Embroidery & n.a. & n.a. & n.a. & n.a. & n.a. & n.a. & n.a. & n.a. & $\begin{array}{l}\text { Pseudopurpurin, } \\
\text { munjistin, lucidin, } \\
\text { xanthopurpurin, } \\
\text { purpurin, rubiadin, } \\
\text { nordamnacanthal (tr) }\end{array}$ & $\begin{array}{l}\text { Relbunium } \\
\text { hypocarpium }\end{array}$ \\
\hline & PAR-022 & Black & Cotton & $\begin{array}{l}\text { Ground } \\
\text { weave }\end{array}$ & & & & & & & & & $\begin{array}{c}\text { Luteolin-7-O- } \\
\text { glucoside, apigenin-7- } \\
\text { O-glucoside, } \\
\text { chrysoeriol-7-O- } \\
\text { glucoside, luteolin, } \\
\text { apigenin, chrysoeriol, } \\
\text { indigotin, indirubin }\end{array}$ & $\begin{array}{l}\text { indigo-producing } \\
\text { plant + Salix } \\
\text { Humboldtiana } \\
\text { Wild (?) }\end{array}$ \\
\hline & PAR-023 & Brown & Cotton & $\begin{array}{l}\text { Ground } \\
\text { weave }\end{array}$ & & & & & & & & & - & - \\
\hline $\begin{array}{c}1935.32 .0213 / \mathrm{RT}-038075^{*} \\
\text { Fragment }\end{array}$ & PAR-024 & Blue & Camelid & Embroidery & & & & & & & & & Indigotin, indirubin & $\begin{array}{c}\text { indigo-producing } \\
\text { plant }\end{array}$ \\
\hline $\begin{array}{c}\text { 1935.32.0048/RT- } \\
043455^{* *} \\
\text { Tunic }\end{array}$ & PAR-025 & Red & Cotton & $\begin{array}{l}\text { Ground } \\
\text { weave }\end{array}$ & & & & & & & & & $\begin{array}{l}\text { Pseudopurpurin, } \\
\text { munjistin, lucidin, } \\
\text { xanthopurpurin, } \\
\text { purpurin }\end{array}$ & $\begin{array}{l}\text { Relbunium } \\
\text { hypocarpium }\end{array}$ \\
\hline \multirow{2}{*}{$\begin{array}{l}\text { 1932.16.0165 } \\
\text { Fragment of a border }\end{array}$} & PAR-030 & White & Cotton & $\begin{array}{l}\text { Ground } \\
\text { weave }\end{array}$ & & & & & & & & & n.a. & - \\
\hline & PAR-031 & White & Cotton & $\begin{array}{l}\text { Ground } \\
\text { weave }\end{array}$ & & & & & & & & & n.a. & - \\
\hline \multirow{2}{*}{$\begin{array}{l}\text { 1935.32.0122a } \\
\text { Mantle }\end{array}$} & PAR-032 & White & Cotton & $\begin{array}{l}\text { Ground } \\
\text { weave }\end{array}$ & & & & & & & & & n.a. & - \\
\hline & PAR-033 & White & Cotton & $\begin{array}{l}\text { Ground } \\
\text { weave }\end{array}$ & & & & & & & & & n.a. & - \\
\hline \multirow{2}{*}{$\begin{array}{c}\text { 1935.32.0122b } \\
\text { Tunic }\end{array}$} & PAR-034 & White & Cotton & $\begin{array}{l}\text { Ground } \\
\text { weave }\end{array}$ & & & & & & & & & n.a. & - \\
\hline & PAR-035 & White & Cotton & $\begin{array}{l}\text { Ground } \\
\text { weave }\end{array}$ & & & & & & & & & n.a. & - \\
\hline \multirow[t]{2}{*}{$\begin{array}{l}1935.32 .0173 \\
\text { Border }\end{array}$} & PAR-036 & Green & Camelid & Embroidery & & & & & & & & & $\begin{array}{l}\text { Quercetin, methyl- } \\
\text { quercetin, } \\
\text { pseudopurpurin, } \\
\text { munjistin, } \\
\text { xanthopurpurin, } \\
\text { purpurin, indigotin, } \\
\text { indirubin }\end{array}$ & $\begin{array}{c}\text { Relbunium } \\
\text { hypocarpium + } \\
\text { indigo-producing } \\
\text { plant + quercetin } \\
\text { based yellow dye }\end{array}$ \\
\hline & PAR-037 & Green & Camelid & Embroidery & & & & & & & & & Indigotin, indirubin & $\begin{array}{c}\text { indigo-producing } \\
\text { plant }\end{array}$ \\
\hline
\end{tabular}

The colour of the cells for each element is related to its peak area intensity in XRF spectra, from the most intense (white) to the lowest (black) with one or two shades of grey in between (n.a. not analysed, tr traces)

* Repatriated from the National Museum of World Culture (NMWC; Gothenburg; Sweden) to the Museo Nacional de Arqueología, Antropología e Historia del Perú (MNAAHP; Lima; Peru) in 2014

** Repatriated from the National Museum of World Culture (NMWC; Gothenburg; Sweden) to the Museo Nacional de Arqueología, Antropología e Historia del Perú (MNAAHP; Lima; Peru) in 2017 


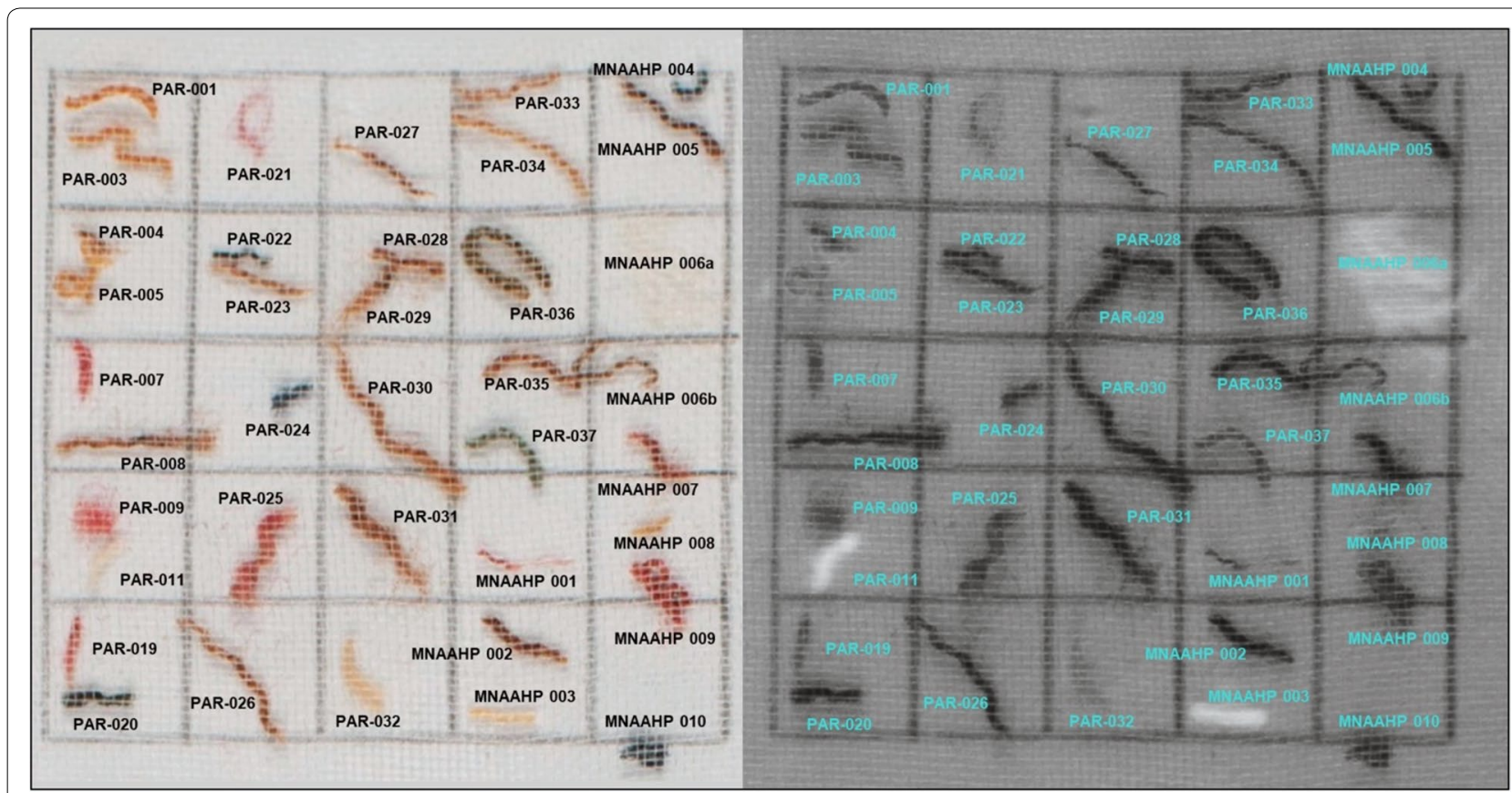

Fig. 3 Visible light photograph (left) and UV induced visible fluorescence (right) image of all the samples analysed. UV induced visible fluorescence images contained also some UV reflectance due to an insufficient UV cut-off filter, thus image rendered to black and white and contrast enhanced

(See figure on next page.)

Fig. 4 a HPLC-DAD (extracted at $450 \mathrm{~nm}$ ) of the extracts of all the red threads of the sample set (all chromatograms are presented in the same scale, and stacked for the sake of clarity); $\mathbf{b} \mathrm{HPLC}-\mathrm{ESI}-\mathrm{Q}-\mathrm{ToF}$ extracted ion chromatograms (EIC) of anthraquinones $\left(\mathrm{C}_{15} \mathrm{H}_{8} \mathrm{O}_{7}, \mathrm{C}_{15} \mathrm{H}_{8} \mathrm{O}_{6}, \mathrm{C}_{15} \mathrm{H}_{10} \mathrm{O}_{5}\right.$, $\mathrm{C}_{14} \mathrm{H}_{8} \mathrm{O}_{4}, \mathrm{C}_{14} \mathrm{H}_{8} \mathrm{O}_{5}, \mathrm{C}_{15} \mathrm{H}_{10} \mathrm{O}_{4}$ ) from the extracts of sample MNAAHP-009. Negative acquisition mode

(21.6 min) (Fig. 5). The analysis performed with HPLCHRMS confirmed these attributions and revealed the presence of isatin $(m / z=146.023)$, indigotin precursor, in MNAAHP-004. These indigoids are the well-known molecular markers of various vegetal species [35], but in the Peruvian area the most common indigo-producing species are Indigofera suffruticosa and Cybistax antisyphilitica [34]. The profiles of the extracts from reference textiles dyed with these two botanical sources have not been investigated yet, thus they are both likely candidates for the blue Paracas samples [29, 36, 37]. The indigotin/indirubin ratio (in this case, the ratio between the DAD peak area of indigotin and indirubin $\left(\mathrm{A}_{\text {Ind }} / \mathrm{A}_{\text {Inr }}\right)$ integrated at the maximum of absorbance in the $550-650 \mathrm{~nm}$ range) cannot provide a criterium to unambiguously identify the specific indigo plants used, given that the quantity of indigoid dyes depends on extraction procedures and dyeing recipes [38], but can highlight differences or similarities amongst the three blue samples analysed. In samples PAR-024 and MNAAHP-010 the chromatographic peak area of indigotin is three times that of indirubin $\left(\mathrm{A}_{\text {Ind }} / \mathrm{A}_{\text {Inr }} 3.2\right.$ and 3.1, respectively), while in sample MNAAHP-004 it is nearly the same (1.2). This might suggest the use of a different recipe or a different dye source.

Finally, in general, all the samples show a relevant amount of indirubin, which is seldom detected in European Indigofera species [35]. This is in accordance with previous evidences collected from the analysis of some pre-Hispanic Andean cotton blue fabrics [39]. A plausible explanation for this difference may consist in a South American vat dyeing technology that favoured the formation and uptake of indirubin by the yarn.

\section{Green and yellow threads}

The yellow threads (samples MNAAHP-008, PAR-001, PAR-003 and PAR-005) and the green ones (PAR-036 and PAR-037) will be discussed together, since green hues were usually obtained by consecutively applying yellow and blue dyes. The HPLC-DAD chromatograms of the samples are shown at max absorbance of 300$400 \mathrm{~nm}$ (yellow) and 500-600 nm (blue) and reported in Additional file 1: Figure S3a, b. The two green samples (PAR-037 and PAR-036) both contain indigotin 

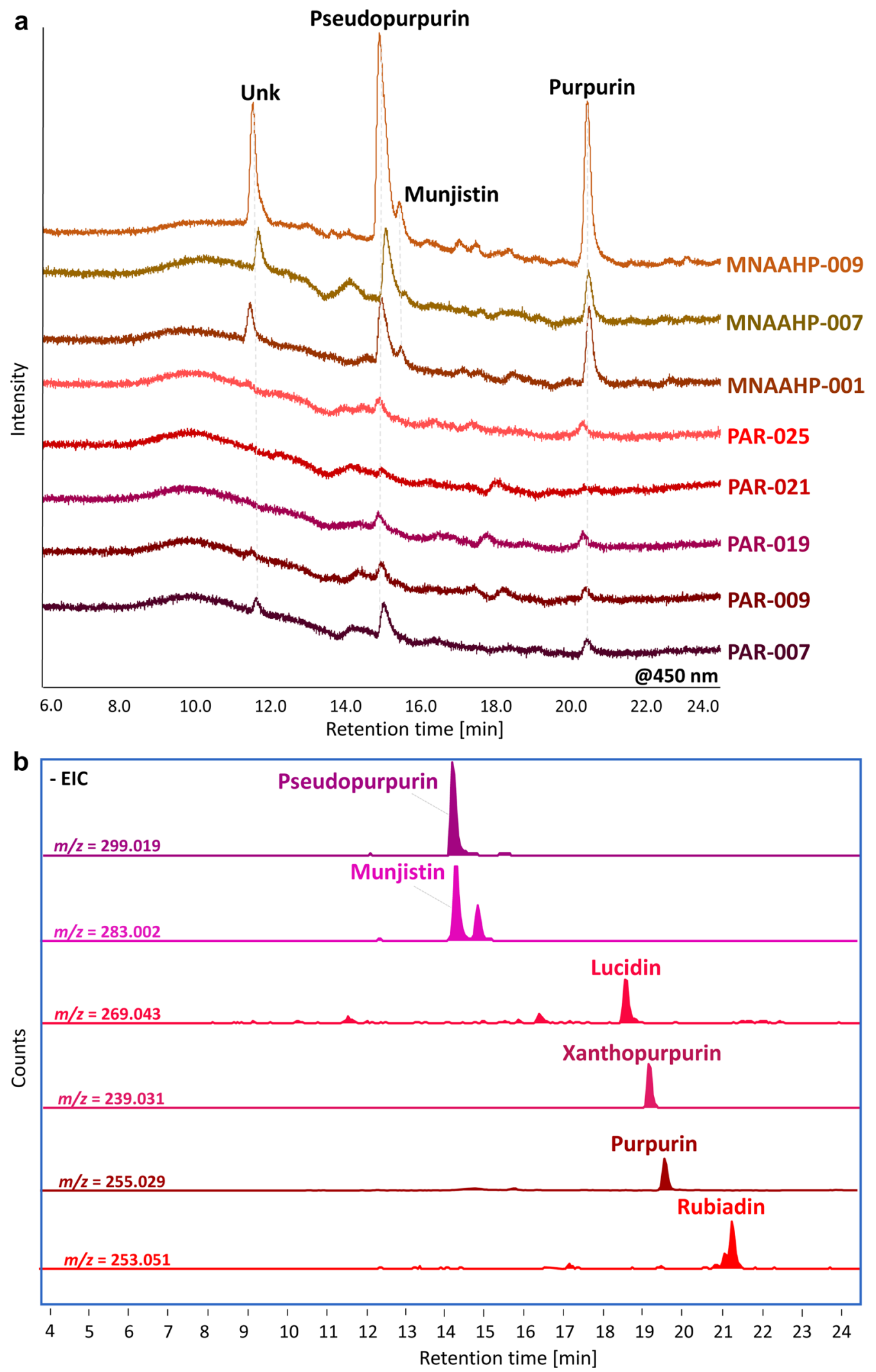


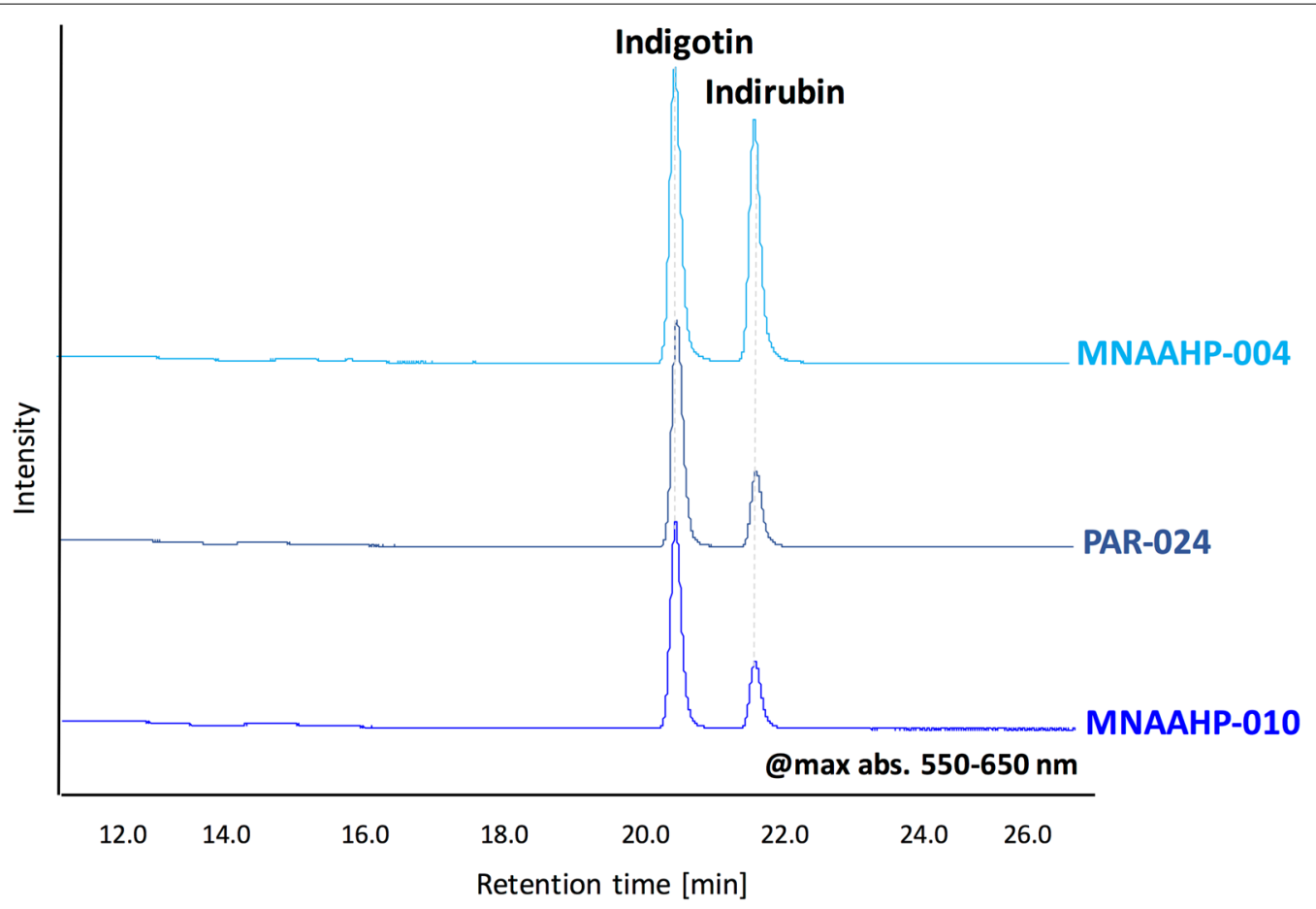

Fig. 5 HPLC-DAD (extracted at max abs 550-650 nm) of the extracts of all the blue threads analysed (all chromatograms are presented in the same scale and stacked for the sake of clarity)

and indirubin. Indigotin was also detected in the yellow sample MNAAHP-008, along with three unknown blue compounds $\left(\mathrm{b}_{1-3}\right)$ in the 19.7-22.6 min time range, whose UV-Vis spectra do not allow a straightforward interpretation but resemble those of synthetic blue dyes (Additional file 1: Figure S3d). No further information on these components was obtained by mass spectrometric detection in negative, nor in positive ionization mode. The presence of indigotin and other blue components in this sample might be due to a contamination of the yellow thread from adjacent fibres. This textile is supported on a modern blue cloth in storage and the most likely explanation is that some fibres from the support fabric were accidentally sampled along with the yellow thread MNAAHP-008.

With regard to the yellow components, the HPLCDAD chromatograms relative to all the green and yellow threads show very small peaks, with the exception of those in the 18.6-21.8 min time range $\left(\mathrm{g}_{1-5}\right)$ in the green sample PAR-036, whose UV-Vis spectra are typical of yellow flavonoid compounds (Additional file 1: Figure S3c). High Resolution MS allowed us to identify these yellow flavonoids as quercetin $(\mathrm{m} / z=301.033)$, and methylquercetin $(m / z=315.049)$. The comparison between the profiles of reference alpaca and sheep yellow dyed fibres from the Saltzman collection materials (Baccharis floribunda, Kageneckia lanceolata, Hypericum larcifolium) and that of sample PAR-036 allowed us to exclude that any of these three quercetin containing species was used for the Paracas fibres under study $[17,18]$.

Besides blue indigoids (indigotin and indirubin, both $m / z=261.064)$ and yellow flavonoids, red anthraquinones were also detected in sample PAR-036 (pseudopurpurin, $m / z=299.019$, xanthopurpurin, $m / z=239.031$, purpurin, $m / z=255.029$ ), as shown in the EIC chromatograms (Fig. 6a), whose profile suggests that the source of red is Relbunium. Evidence of textiles from Paracas Necrópolis dyed with a mixture of yellow and blue vegetal source to yield green nuances or with red (Relbunium species) and blue for the violet hues have already been

(See figure on next page.)

Fig. $6 \mathrm{HPLC}-\mathrm{ESI}$-Q-ToF extracted ion chromatograms (EIC) of: a flavonoids $\left(\mathrm{C}_{15} \mathrm{H}_{10} \mathrm{O}_{7}, \mathrm{C}_{16} \mathrm{H}_{12} \mathrm{O}_{7}\right)$, anthraquinones $\left(\mathrm{C}_{15} \mathrm{H}_{8} \mathrm{O}_{7}, \mathrm{C}_{15} \mathrm{H}_{8} \mathrm{O}_{6}, \mathrm{C}_{15} \mathrm{H}_{10} \mathrm{O}_{6}\right.$, $\left.\mathrm{C}_{14} \mathrm{H}_{8} \mathrm{O}_{5}\right)$ and indigoids $\left(\mathrm{C}_{16} \mathrm{H}_{10} \mathrm{~N}_{2} \mathrm{O}_{2}\right)$ from the extracts of sample PAR-036; $\boldsymbol{b}$ flavonoids $\left(\mathrm{C}_{21} \mathrm{H}_{20} \mathrm{O}_{11}, \mathrm{C}_{21} \mathrm{H}_{22} \mathrm{O}_{11}, \mathrm{C}_{21} \mathrm{H}_{22} \mathrm{O}_{10}, \mathrm{C}_{15} \mathrm{H}_{12} \mathrm{O}_{6}, \mathrm{C}_{15} \mathrm{H}_{10} \mathrm{O}_{6}\right.$, $\mathrm{C}_{15} \mathrm{H}_{12} \mathrm{O}_{5}$ ) from the extracts of sample PAR-001. Negative acquisition mode 

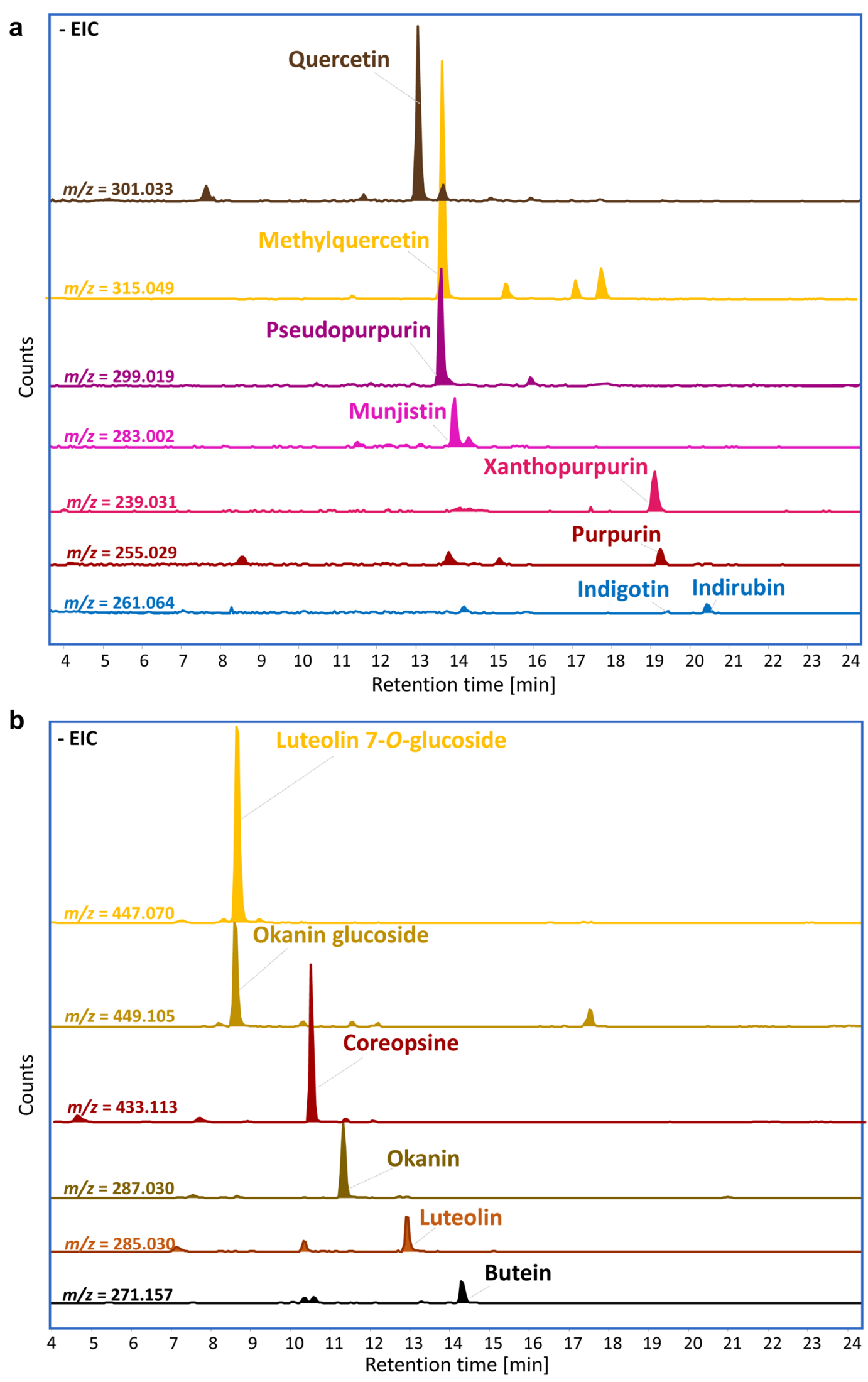
mentioned in the literature [21], but no previous report is available on any yellow-blue-red recipes for obtaining green.

With regard to the other green sample PAR-037, the yellow component was not detected by either HPLCDAD or by HPLC-HRMS, neither in positive nor in negative detection mode. Since indigotin and indirubin were detected in this sample (see above), different hypotheses may explain the final green colour. XRF analysis showed that this thread contains copper, which may be responsible for the green hue. Alternatively, the yellow compounds could have faded so severely that our techniques are unable to detect them (see for instance the reactivity of flavonoids as shown in [40]); or the fibre itself could possess a brownish-yellow colour, which combined with blue produces the final green (the pigmentation of South American camelids has already been described in [41]); or a specific recipe may have been used to yield a greenish hue with indigo-producing plants (as shown in [42]). It is interesting to note that the two green threads belong to the same textile, 1935.32.0173, where an embroidered green ground now shows patches of different hues that were presumably once evenly coloured (Fig. 1). PAR-036 was collected from an area of turquoise ground and PAR037 from the more dominant olive-green ground.

The application of HPLC-HRMS allowed us to characterize in detail the source used in the yellow threads. Several flavonoids were unequivocally identified in samples PAR-001, PAR-003 and PAR-005 (the EIC chromatograms of yellow sample PAR-001 are presented in Fig. 6b): luteolin 7-O-glucoside $(\mathrm{m} / z=447.070)$, okanin glucoside $(m / z=449.105)$, coreopsin $(m / z=433.113)$, okanin $(m / z=287.030)$, luteolin $(m / z=285.030)$ and butein $(m / z=271.057)[43,44]$. Okanin and butein and their glucosides occur in several species, such as Bidens, native to South America [45], but in this case, the positive matching with the profile of the extracts of the petals of Cosmos sulphureus, performed in the same conditions, allowed us to suggest that the latter is the raw source used for dyeing [46]. The use of Cosmos sulphureus for dyeing in yellow-orange hues is reported in the literature $[26,27]$ but, to the best of our knowledge, this is the first time that it has been identified in ancient textiles.

Finally, the extract of the yellow sample MNAAHP-008 contains luteolin-7-O-glucoside, apigenin-7-O-glucoside, chrysoeriol-7-O-glucoside, luteolin, apigenin, and chrysoeriol. This profile is very similar to that of Reseda luteola, one of the most used yellow dyes in the Old World, and matches with the so-called "[LUTE-APIG] group" described by Wouters and Rosario-Chirinos [21]. More specifically, the profile is also extremely similar to that provided in [36] for the extract of the leaves of the South American Salix Humboldtiana Wild. At present, only a tentative attribution can be made, since Antúnez de Mayolo identified fifteen Andean plant species as sources of yellow dyes [29], and among them Zumbhul [47] described three plants as luteolin-containing species: Alnus jorulensis, Baccharis genistelloides, and Bidens andicola, whose chromatographic profiles are not available in the literature yet.

\section{Brown, black and grey threads}

The HPLC-DAD profiles of all the brown (samples MNAAHP-002, MNAAHP-005, PAR-008 e PAR023), black (samples PAR-020 and PAR-022) and grey (MNAAHP-006b) samples (Additional file 1: Figure S4) are rather featureless (no peaks). In MNAAHP-002 extract several peaks were detected and assigned to flavonoid compounds: luteolin-7-O-glucoside (10.7 $\mathrm{min})$, apigenin-7-O-glucoside (12.2 $\mathrm{min})$, chrysoeriol-7- $O$ glucoside (12.6 $\mathrm{min})$, luteolin $(14.8 \mathrm{~min})$, apigenin $(16.3 \mathrm{~min})$ and chrysoeriol $(16.7 \mathrm{~min})$. The analysis by HPLC-HRMS confirmed the attribution of these peaks for sample MNAAHP-002, detected the further presence of indigotin and indirubin in the extract, and highlighted the same composition for the black threads of PAR-022 and PAR-020. In particular, the EIC profiles (the chromatograms of PAR-022 are provided in Fig. 7) featured: luteolin-7- $O$-glucoside $(m / z=447.070)$, apigenin-7- $O$ glucoside $(m / z=431.072)$, chrysoeriol-7-O-glucoside $(m / z=461.103)$, luteolin $(m / z=285.030)$, apigenin $(m / z=269.038)$ and chrysoeriol $(m / z=299.045)$ [48-50], in addition to indigotin and indirubin $(m / z=261.064)$.

The presence of indigoids accounted for the dark coloration of the threads. Due to the lack of reference materials with comparable profiles, the additional flavonoid raw material used can only be assigned to the "[LUTE-APIG] group" mentioned above for sample MNAAHP-008. Interestingly, all the textiles that contained "[LUTE-APIG] group" molecular markers, also contained indigotin and indirubin, thus suggesting that this dye source was preferably used in combination with an indigoid dye.

In the grey sample MNAAHP-006b only luteolin was detected, thus no clear attribution of the raw material used can be inferred. The high content of iron revealed by XRF (see Sect. "Analysis of the inorganic components") suggests that it was used as a mordant, to provide the thread with a grey colour, as generally occurring for iron-tannate dyes.

Finally, the brown samples (PAR-008, PAR-023 and MNAAHP-005) do not contain any dyes above detection limit. Dark hues are often provided by tannin dyes, but none of their most common molecular markers, such as gallic acid and ellagic acid, were detected [51]. Nevertheless, the use of high-molecular weight condensed 


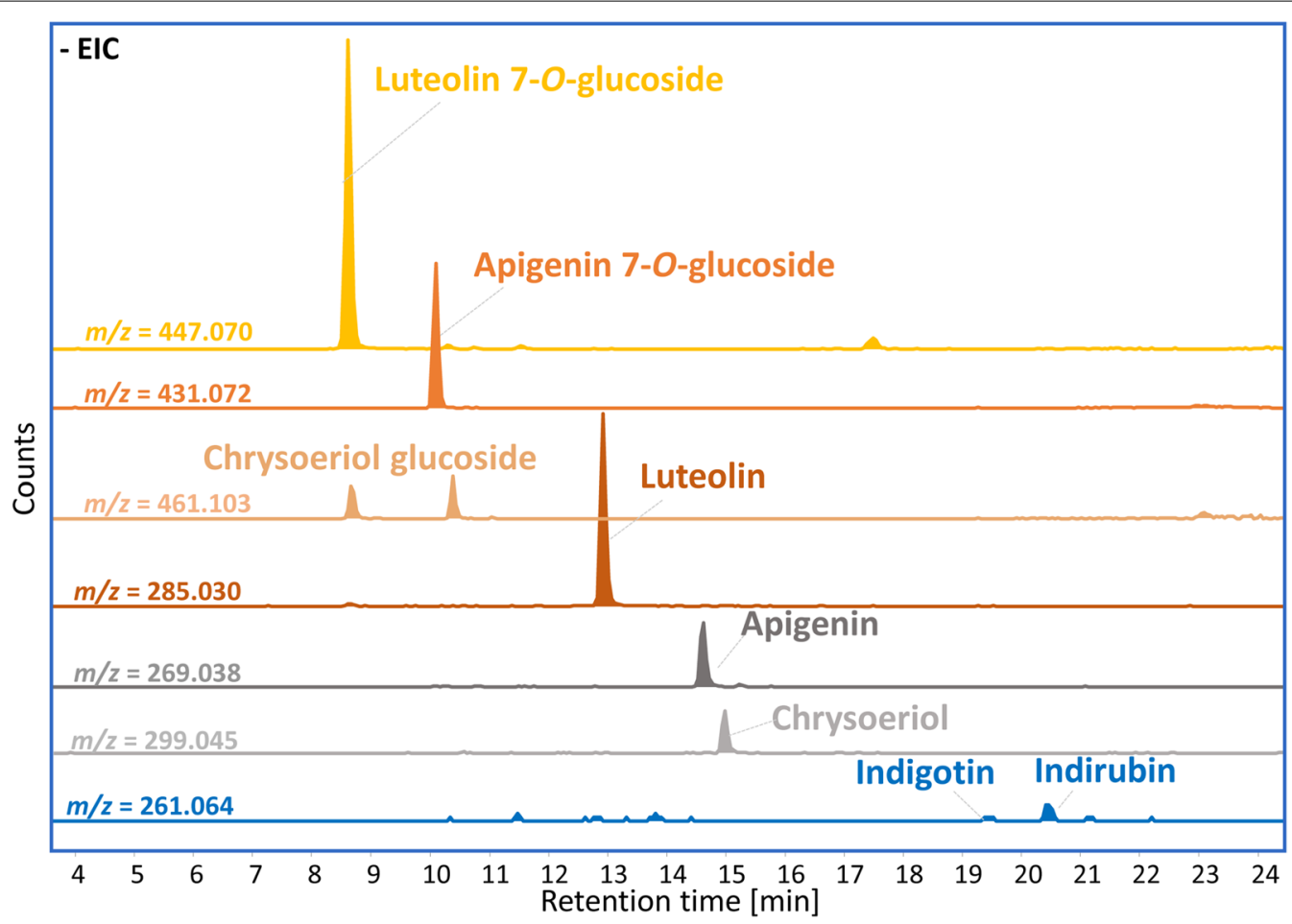

Fig. $7 \mathrm{HPLC}-\mathrm{ESI}$-Q-ToF extracted ion chromatograms (EIC) of flavonoids $\left(\mathrm{C}_{21} \mathrm{H}_{20} \mathrm{O}_{11}, \mathrm{C}_{21} \mathrm{H}_{20} \mathrm{O}_{10}, \mathrm{C}_{22} \mathrm{H}_{22} \mathrm{O}_{11}, \mathrm{C}_{15} \mathrm{H}_{10} \mathrm{O}_{6}, \mathrm{C}_{15} \mathrm{H}_{10} \mathrm{O}_{5}, \mathrm{C}_{16} \mathrm{H}_{12} \mathrm{O}_{6}\right)$ and indigoids $\left(\mathrm{C}_{16} \mathrm{H}_{10} \mathrm{~N}_{2} \mathrm{O}_{2}\right)$ from the extracts of sample PAR-022. Negative acquisition mode
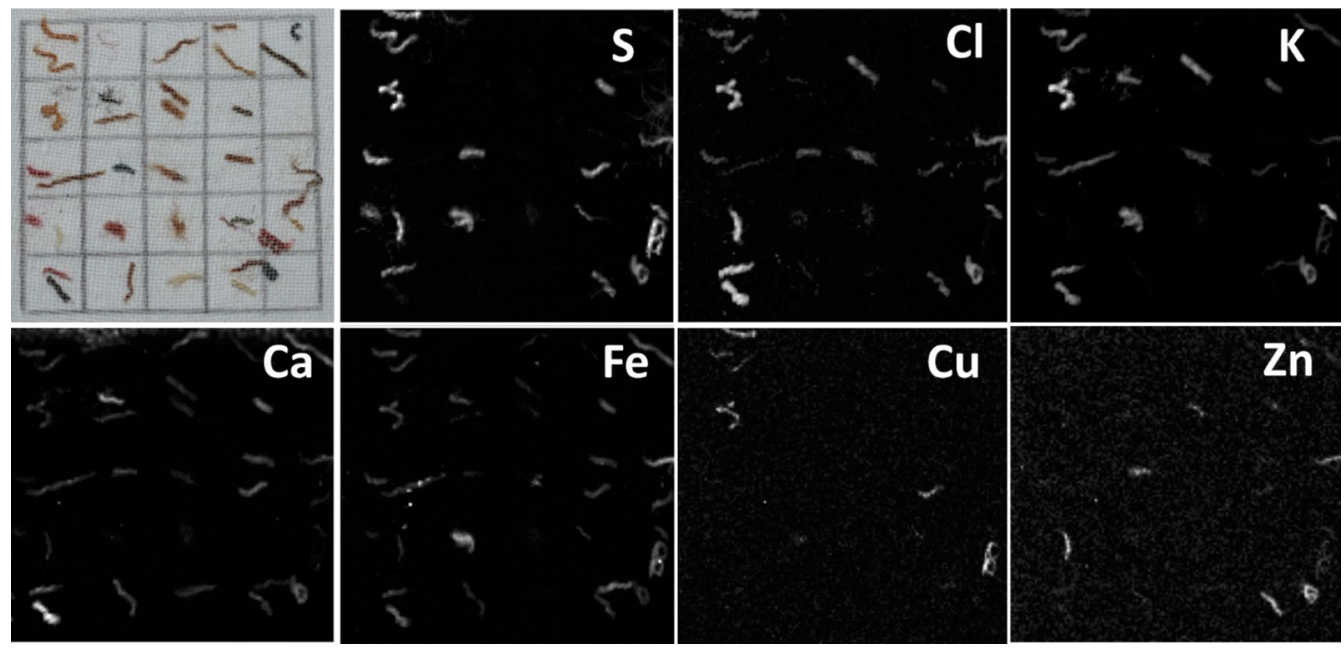

Fig. 8 UXRF maps for sulphur, chlorine, potassium, calcium, iron, copper and zinc measured on all the samples analysed

tannins, hardly detectable by a liquid chromatographic approach, cannot be excluded. An alternative explanation is that the brown colour was provided by the natural pigmentation of the raw cotton fibres.

\section{Analysis of the inorganic components}

In $\mu$ XRF mapping every pixel corresponds to a spectrum. Separate grayscale maps are generated for each element detected, where the brightest areas correspond to the highest peak areas, while black represents the lowest values or absence of the peak (Fig. 8). 
In order to be able to tabulate and compare data from the generated maps, the peak intensities were visually sorted into three or four categories from brightest (white) to darkest (black) with one or two shades of grey in between, see Table 1 . The data were interpreted by crosschecking the results with the detected dyestuffs, in order to assess whether additives or mordants could be identified. Moreover, the results obtained on single threads were compared with those achieved by micro-XRF elemental maps of textile fragments in a previous study [3]. It is important to bear in mind that the most common mordant, alum (an Al salt), could not be detected. Aluminium is at the lower atomic number limit of elements that can be detected by XRF in an air atmosphere. A small peak for aluminium was observed in the accumulated spectra of the maps collected from textile fragments [3]; however, the data maps showed no specific distribution of the relative levels of aluminium between the variously coloured threads. Nevertheless, it appears likely that aluminium mordants were used in the Paracas textiles, given that Peru has natural resources of alum salts [45].

The following observations were made from the comparison amongst the sample set:

- As expected, sulphur was only detected in the camelid fibres (white or grey categories), as it is due to the sulphur-containing proteins in keratin.

- Chlorine also appeared to be generally higher in proteinaceous fibres, although the highest chlorine levels in the entire map are associated to one cellulosic black thread (PAR-020). It is important to note that the chlorine peak appears as a shoulder on the sulphur peak, so its presence in the proteinaceous fibres (rich in sulphur) may be an artefact.

- Potassium was also relatively high in most colours apart from undyed white cotton. The two highest potassium levels were recorded in yellow threads and could indicate the use of a dyeing auxiliary, possibly an alkaliser in the form of wood ash. The organic dyes of the two yellow threads are different (MNAAHP-008 was dyed with a flavonoid dye of the [lut-apig] group, while PAR-005 was likely dyed with Cosmos sulphureus).

- Calcium was present in every thread, highest in two black cotton threads dyed with Indigofera or Cybistax plus a yellow dye, lowest in most red threads and in the undyed cotton samples (marked as dark grey in Table 1). Thus, calcium also appears to have been a dyeing auxiliary and its elevated presence in the threads heavily dyed with indigoids may indicate the use of a calcium source to alkalise the dyeing vat. Where available, burnt shells are commonly used to that end. In XRF maps of textile fragments [3], calcium was generally highest in the darker shades of brown and black.

- Iron was present in every sample but generally was the lowest in undyed and blue threads; this may imply that iron was a mordant for the red and yellow dyes, also when used with indigo for green, brown and black threads. Iron was highest in the red cotton thread PAR-025 dyed with Relbunium and in a grey camelid thread (MNAAHP-006b) that contained an unknown luteolin-based yellow dye. In the latter case, the grey colour might have been purposely obtained by using an iron mordant with a flavonoid dye. Alternatively, iron may have been present in the water used for dyeing; implying that a urine vat for the indigoid dyes could explain the lower levels of iron in the blue threads. Iron was also relatively low in the blue areas of mapped textile fragments [3], where generally iron was highest in some of the darkest black and brown shades but also in some quite light grey and yellow shades.

- Copper was barely detectable above the background but yielded a clear map with relevant signals in several red, yellow and one green camelid threads. In particular, three samples of yellow camelid embroidery, possibly dyed with Cosmos sulphureus, all contained relatively high amounts of copper. This may suggest that copper was used as a mordant. This distribution is very consistent with the data obtained for the mapping of the whole textile fragment 1935.32.0211a, as presented in [3].

- Zinc was barely detectable, but the highest amounts can be clearly pinpointed on the two undyed white camelid threads, the two blue camelid threads and the grey camelid thread with an unknown luteolinbased yellow dye. This is also consistent with the XRF mapping of the textile fragments [3] where zinc was mostly detected in light-coloured areas of grey, white and beige. The use or function of zinc in these fibres remains unknown.

\section{Compression tests}

Compression tests results are presented in Fig. 9. Compression tests for the cotton showed that the white threads are mostly in reasonable condition while the brown and black threads tend to have a wider distribution of conditions, with a higher number of weak or very fragile brown samples compared to the white samples. Of the eleven brown cotton threads tested, four were also analysed by XRF and HPLC-DAD-HRMS. Three of those, one from each category: flexible, weak, fragile, 


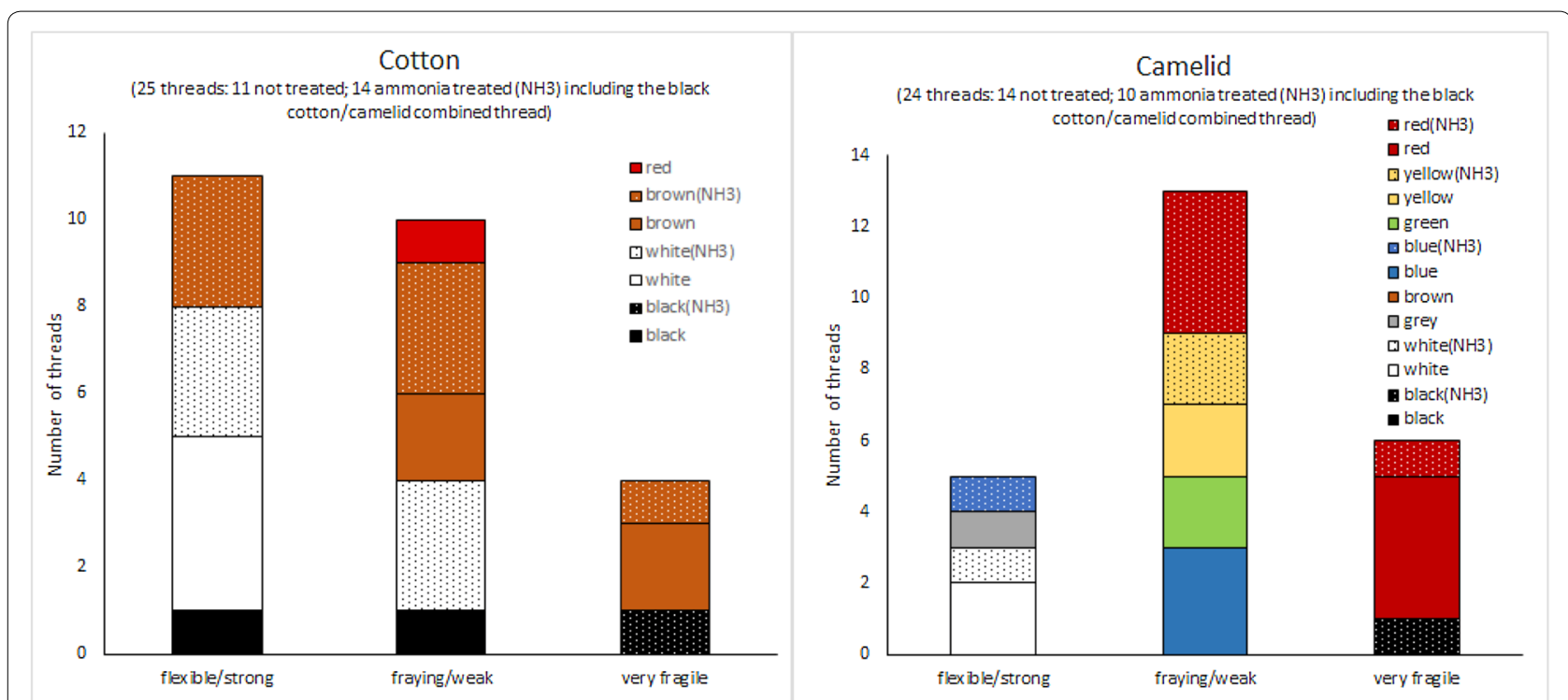

Fig. 9 Bar charts showing in the results from the compression tests as number of threads in three categories (flexible/strong; fraying/weak; very fragile) ordered by material (cotton/camelid), colour (as indicated) and treatment (ammonia treated threads have a dotted fill)

were most likely undyed, while the fourth one (weak) was dyed with a combination of indigo-producing vegetal source and a yellow dye.

Similarly, the undyed white or grey camelid yarns tend to still be flexible/strong whilst the red and possibly the black cotton threads tend to be in the worst conditions.

Samples from ammonia treated cotton and camelid textiles occur in every category suggesting that the treatment did not have a lasting, or any, effect, except perhaps for red camelid samples. Interestingly, the only red camelid samples that are not classified as very fragile are those that underwent the ammonia treatment. These samples come from different textiles, and do not vary in terms of organic dye or inorganic content. In detail, the dyes in seven of the nine red threads were analysed and all were identified as Relbunium species, and the inorganic components in the red dyed camelid samples were consistent. One sample was relatively high in copper (very fragile), a second one relatively high in iron (weak), while almost all were relatively low in calcium compared to the other colours. Notwithstanding this, the number of observed specimens is too low and the condition assessment method too subjective to conclusively state that the ammonia treatment had any preservative effect.

\section{Conclusions}

The combined analytical approach allowed us to formulate substantiated hypotheses on the mordants and other inorganic auxiliaries and the wide plethora of vegetal sources employed by the Paracas civilization for dyeing cotton and camelid fibres.

The mild sample pre-treatment adopted was effective in extracting the dyes from the cotton and camelid fibres, and the consecutive application of HPLC-DAD and HPLC-HRMS techniques allowed us to assess the composition of the dyestuff for most of the samples.

All the red threads were possibly dyed with Relbunium species, most likely Relbunium hypocarpium or a mixture containing this species. Animal dye sources, such as cochineal, were not detected in any sample. Besides alum, which cannot be detected by XRF mapping in air, both iron and copper have been detected in some red and yellow threads, and in the case of iron also in a grey shade. These results are consistent with previous work carried out on textile fragments [3] and suggest the deliberate use of iron and copper in various dye formulations.

The blue, green and black samples were dyed with indigo-producing vegetal source such as Indigofera suffruticosa or Cybistax antisyphilitica species, alone or in combination with yellow dyes. Indigoid plants are the most commonly used sources of natural blue dyes, and the samples dyed with them contained a relevant amount of calcium, possibly used as an auxiliary in the vat dyeing process.

While the source of yellow employed for dyeing the yellow threads are possibly the petals of Cosmos sulphureus, detected for the first time in historical textiles and maybe used with a copper mordant, the identification of the yellow raw material used in mixture with indigotin and indirubin in green, brown and black 
threads is not straightforward. The HPLC-HRMS profiles of these samples are rich in flavonoids and their relative glucosides, resembling those of Reseda luteola, a typical European dye plant. Among the hundreds of yellows available in the Andean area, all extracted from plants [29, 47], the composition of Salix Humboldtiana Wild closely resembles that of Reseda luteola. Thus, it is the most likely candidate raw source used for dyeing the Paracas samples. However, it is not possible to exclude other dye sources, not described nor characterized in detailed yet.

Some brown threads and all white ones are undyed; thus, their colour is given by the natural colour of camelid or cotton. The grey sample is dyed by a luteolin based raw material and shows relatively high levels of both iron and zinc.

The results reported in this paper contribute to filling the knowledge gap on the dyeing materials of Andean culture, providing important hints on the mordanting processes and recipes adopted in textiles manufacturing.

\section{Supplementary information}

Supplementary information accompanies this paper at https://doi. org/10.1186/s40494-020-00461-5.

Additional file 1: Table S1. List of the Paracas fibres with their relative description and analysis performed. Table S2. Interpretation of the additional XRF map collected from 23 of the fibre samples. The colour of the cells for each element is related to its peak area intensity in XRF spectra, from the most intense (white) to the lowest (black) with one shade of grey in between. Figure S1. a) HPLC-DAD (extracted at $450 \mathrm{~nm}$ ) b) HPLC-DAD (extracted at max abs 450-550 nm) c) HPLC-DAD (extracted at max abs $550-650 \mathrm{~nm}$ ) of the extracts of all the white fibers analyzed (all chromatograms are presented in the same scale, and stacked for the sake of clarity). Figure S2. Compound labelled as Unk in Fig. 4a: a) UV-Vis spectrum; b) mass spectrum; c) product-ion spectrum. Figure S3. a) HPLC-DAD (extracted at max abs 300-400 nm) b) HPLC-DAD (extracted at max abs 550-650 nm) of the extracts of all the yellow and green fibers analyzed; c) UV-Vis spectra of the g1-5 compounds labelled in Figure S3 a; d) UV-Vis spectra of the b1-3 compounds labelled in Figure S3 b (all chromatograms are presented in the same scale, and stacked for the sake of clarity). Figure S4. HPLC-DAD (extracted at max abs 300-400 nm) of the extracts of all the brown (P008, P023, M005 and M002), black (P020 and P022) and grey (M006b) fibers analyzed (all chromatograms are presented in the same scale, and stacked for the sake of clarity).

\section{Abbreviations}

ACN: Acetonitrile; DMF: Dimethyl formamide; FA: Formic acid; HPLC-DAD: High performance liquid chromatography coupled with a diode array detector; HPLC-ESI-Q-ToF: High performance liquid chromatography interfaced through an electrospray ion source to a quadrupole-time of flight mass spectrometric detector; HPLC-HRMS: High performance liquid chromatography coupled with high-resolution mass spectrometry; IR: Infrared radiation; MNAAHP: Museo Nacional de Arqueología, Antropología e Historia del Perú (Lima; Peru); MS: Mass spectrometry or mass spectrum; MS/MS: Tandem mass spectrometry or tandem mass spectrum; $\mathrm{Na}_{2}$ EDTA: Ethylenediaminetetraacetic acid disodium salt; NIR: Near infrared radiation; NMWC: National Museum of World Culture (Gothenburg; Sweden); UV: Ultraviolet radiation; XRF: X-ray fluorescence.

\section{Acknowledgements}

Kaj Thuresson and Magnus Mårtensson are acknowledged for assistance with XRF and technical photography at the Heritage Laboratory, Swedish National Heritage Board. Carmen Thays Delgado and María Ysabel Medina Castro are acknowledged for assistance with sampling at the National Museum of Archaeology, Anthropology, and History in Lima, Peru. Dr. David Buti (Institute of Heritage Science - CNR, Italy) is acknowledged for providing us with the Cosmos sulphureus petals used as reference material in this study. University of Pisa and Prof. Francesca Modugno are acknowledged for funding FS's scholarship under the BIHO2019 programme.

\section{Authors' contributions}

$\mathrm{AJ}$ and $\mathrm{MH}$ selected the samples and designed the experiment. FS, MB, AJ, and $\mathrm{MH}$ performed the analyses and ID contributed in interpreting the chromatographic and mass spectrometric data. All authors equally contributed in drafting the manuscript. All authors read and approved the final manuscript.

\section{Funding}

No funding was received.

\section{Availability of data and materials}

The datasets used and analysed during the current study are available from the corresponding author on reasonable request.

\section{Competing interests}

The authors declare that they have no competing interests.

\section{Ethics approval and consent to participate}

Not applicable.

\section{Author details \\ ${ }^{1}$ Department of Chemistry and Industrial Chemistry, University of Pisa, Via Moruzzi, 13, 56126 Pisa, Italy. ${ }^{2}$ Department of Museums, The Cultural Administration, City of Gothenburg, Norra Hamngatan 8, 41114 Gothenburg, Sweden. ${ }^{3}$ Heritage Laboratory, Swedish National Heritage Board, Box 1114 , 62122 Visby, Sweden.}

Received: 27 July 2020 Accepted: 1 November 2020

Published online: 27 November 2020

\section{References}

1. Canales EL. La Cultura Paracas. Paracas Exhib Cat. Museo Nacional de Arqueologia, Antropologia e Historia del Peru; 2013. p. 11-26.

2. Javér A. Analysis of Paracas fibre material from the Gothenburg Collection. In: Bjerregaard L, Peters A, editors. PreColumbian text conf VII / Jornadas Text PreColombinos VII. Lincoln: Zea Books; 2017. p. 398-404.

3. Javér A, Hacke M, Delegado CT, Thuresson K. Paracas textiles-colour and condition. Investigation of the mordants and state of degradation of the Paracas textile collections in Peru and Sweden. ICOM-CC 18th Trienn Conf Prepr Copenhagen. 2017.

4. D. C. A wealth of yellows: plants containing flavonoids. Nat Dye Sources, Tradit Technol Sci. London: Archetype Publications Ltd; 2007.

5. Boytner R. Class, control, and power: the anthropology of textile dyes at Pacatnamu. In: Young-Sánchez M, Simpson FW, editors. Andean Text Tradit Papers from 2001 Mayer Center Symposium Denver Art Museum. Denver, CO. 2006. p. 44-74.

6. Fester GA, Cruellas J. Colorantes de Paracas. Rev del Mus Nac. 1934;3:154-6.

7. Jakes K, Katon J, Martoglio P. Identification of dyes and characterization of fibers by infrared and visible microspectroscopy: application to Paracas textiles. Archaeometry. 1990;90:305-15.

8. Martoglio PA, Bouffard SP, Sommer AJ, Katon JE, Jakes KA. Unlocking the secrets of the past: the analysis of archaeological textiles and dyes. Anal Chem. 1990;62:1123A-1128A.

9. Saltzman M. The identification of dyes in archaeological and ethnographic textiles. In: Giles CF, editor. Archaeol Chem. Washington: American Chemical Society; 1978a. p. 172-85. 
10. Saltzman M. Analysis of dyes in museum textiles or, you can't tell a dye by its color. In: CC Mc Lean, editor. Text conservation symposium in honor of Pat Reeves. Los Angeles: Lacma; 1986. p. 27-39.

11. Wallert A, Boytner R. Dyes from the Tumilaca and Chiribaya cultures, south coast of Peru. J Archaeol Sci. 1996;23:853-61.

12. Yacovleff E, Muelle JC. Notas al Trabajo "Colorantes de Paracas." Rev del Mus Nac. 1934;3:157-63.

13. Degano I, Colombini MP. Multi-analytical techniques for the study of pre-Columbian mummies and related funerary materials. J Archaeol Sci. 2009;36:1783-90

14. Bernardino ND, de Faria DLA, Negrón ACV. Applications of Raman spectroscopy in archaeometry: an investigation of pre-Columbian Peruvian textiles. J Archaeol Sci Rep. 2015:4:23-31.

15. Claro A, Melo MJ, de Melo JSS, van den Berg KJ, Burnstock A, Montague $M$, et al. Identification of red colorants in van Gogh paintings and ancient Andean textiles by microspectrofluorimetry. J Cult Herit. 2010;11:27-34.

16. Burr E. Dye analysis of archaeological Peruvian textiles using surface enhanced Raman spectroscopy (SERS). 2016. PhD Thesis. UCLA. UCLA; 2016

17. Armitage RA, Fraser D, Degano I, Colombini MP. The analysis of the Saltzman Collection of Peruvian dyes by high performance liquid chromatography and ambient ionisation mass spectrometry. Herit Sci. 2019;7:81.

18. Degano I, Magrini D, Zanaboni M, Colombini MP. The Saltzman Collection: a reference database for South American dyed textiles. ICOM-CC 18th Trienn Conf Prepr Copenhagen. 2017.

19. Saito M, Hayashi A, Kojima M. Identification of six natural red dyes by high-performance liquid chromatography. Dye Hist Archaeol. 2003;19:79-87.

20. Zhang X, Boytner R, Cabrera JL, Laursen R. Identification of yellow dye types in pre-Columbian Andean textiles. Anal Chem. 2007;79:1575-82.

21. Wouters J, Rosario-Chirinos N. Dye analysis of pre-Columbian Peruvian textiles with high-performance liquid chromatography and diode-array detection. J Am Inst Conserv. 1992;31:237-55.

22. Degano I, La Nasa J. Trends in high performance liquid chromatography for cultural heritage. Top Curr Chem. 2016;374:20

23. Zhang $X$, Laursen RA. Development of mild extraction methods for the analysis of natural dyes in textiles of historical interest using LC-diode array detector-MS. Anal Chem. 2005;77:2022-5. https://doi.org/10.1021/ ac048380k.

24. Armitage RA, Jakes K, Day C. Direct analysis in real time-mass spectroscopy for identification of red dye colourants in Paracas Necropolis Textiles. Sci Technol Archaeol Res. 2015;1:60-9.

25. Kramell AE, Brachmann AO, Kluge R, Piel J, Csuk R. Fast direct detection of natural dyes in historic and prehistoric textiles by flowprobe ${ }^{\text {TM}}-E S I-H R M S$. RSC Adv. 2017;7:12990-7.

26. Wallert A. The analysis of dyestuffs on historical textiles from Mexico. In: Klein K, editor. The unbroken thread : conserving the textile traditions of Oaxaca. Los Angeles: The Getty Conservation Institute; 1997. p. 57-85.

27. Safford WE. Cosmos Sulphureus, the Xochipalli or flower paint of the Aztecs. J Washingt Acad Sci. 1918;8:613-20.

28. Saltzman M. The identification of dyes in archaeological and ethnographic textiles. In: Carter GF, editor. Archaeological chemistry-II. Washington: American Chemical Society; 1978b. p. 172-85.

29. Antúnez De Mayolo KK. Peruvian natural dye plants. Econ Bot. 1989:43:181-91.

30. Dyer J, Verri G, Cupitt J. Multispectral imaging in reflectance and photoinduced luminescence modes: a user manual. Developed during the EU project CHARISMA, 7th Framework Programme, Grant. British Museum; 2013

31. Wouters J. HPLC high performance liquid chromatography. In: Artioli G, editor. Scientific methods and cultural heritage: an introduction to the application of materials science to archaeometry and conservation science. New York: Oxford University Press; 2010. p. 410-3.
32. Collins S, Davidson RS, Hilchenbach MEC, Lewis DM. The natural fluorescence of wool. Dye Pigment. 1994;24:151-69.

33. Rafaëlly L, Héron S, Nowik W, Tchapla A. Optimisation of ESI-MS detection for the HPLC of anthraquinone dyes. Dye Pigment. 2008;77:191-203.

34. Cardon D. natural dyes: sources, tradition, technology and science. Archetype; 2007.

35. Mantzouris D, Karapanagiotis I, Panayiotou C. Comparison of extraction methods for the analysis of Indigofera tinctoria and Carthamus tinctorius in textiles by high performance liquid chromatography. Microchem J. 2014;115:78-86.

36. Boucherie N, Nowik W, Cardon D. La producción tintórea Nasca : nuevos datos analíticos obtenidos sobre textiles recientemente descubiertos en excavaciones. Mundo Nuevo - Nuevos Mundos, Colloq. 2016;

37. Boucherie N. La couleur dans la civilisation Nasca. Lyon: Université Lumière; 2014.

38. Sanz E, Arteaga A, García MA, Cámara C, Dietz C. Chromatographic analysis of indigo from Maya Blue by LC-DAD-QTOF. J Archaeol Sci. 2012;39:3516-23.

39. Splitstoser JC, Dillehay TD, Wouters J, Claro A. Early pre-Hispanic use of indigo blue in Peru. Sci Adv. 2016. https://doi.org/10.1126/sciadv.15016 23.

40. Degano I, Biesaga M, Colombini MP, Trojanowicz M. Historical and archaeological textiles: an insight on degradation products of wool and silk yarns. J Chromatogr A. 2011;1218:5837-47.

41. Wang $H$, Liu $X$, Wang $X$. Internal structure and pigment granules in colored alpaca fibers. Fibers Polym. 2005;6:263-8.

42. Hartl A, Proaño Gaibor AN, van Bommel MR, Hofmann-de KR. Searching for blue: experiments with woad fermentation vats and an explanation of the colours through dye analysis. J Archaeol Sci Rep. 2015;2:9-39.

43. Deng Y, Lam S-C, Zhao J, Li S-P. Quantitative analysis of flavonoids and phenolic acid in Coreopsis tinctoria Nutt. by capillary zone electrophoresis. Electrophoresis. 2017;38:2654-61.

44. Yang W-Z, Ye M, Qiao X, Wang Q, Bo T, Guo D-A. Collision-induced dissociation of 40 flavonoid aglycones and differentiation of the common flavonoid subtypes using electrospray ionization ion-trap tandem mass spectrometry and quadrupole time-of-flight mass spectrometry. Eur J Mass Spectrom. 2012;18:493-503.

45. Xuan TD, Khanh TD. Chemistry and pharmacology of Bidens pilosa: an overview. J Pharm Investig. 2016;46:91-132.

46. Doménech A, Doménech-Carbó MT, Vázquez de Agredos-Pascual ML. From Maya Blue to "Maya Yellow": a connection between ancient nanostructured materials from the voltammetry of microparticles. Angew Chemie Int. 2011;50:5741-4.

47. Rosario-Chirinos N. Tintes en el Perú prehispánico, virreynal y republican-Dyes in Pre-Hispanic, Viceregal and Republican Peru. Tejidos Milen del Perú_Anc Peruvian Text. Lima: Integra AFP; 1999.

48. Hughes RJ, Croley TR, Metcalfe CD, March RE. A tandem mass spectrometric study of selected characteristic flavonoids. Int J Mass Spectrom. 2001:210-211:371-85.

49. Ma YL, Li QM, Van den Heuvel H, Claeys M. Characterization of flavone and flavonol aglycones by collision-induced dissociation tandem mass spectrometry. Rapid Commun Mass Spectrom. 1998;11:1357-64.

50. Mouri C, Mozaffarian V, Zhang X, Laursen R. Characterization of flavonols in plants used for textile dyeing and the significance of flavonol conjugates. Dye Pigment. 2014;100:135-41.

51. Degano I, Mattonai M, Sabatini F, Colombini MP. A mass spectrometric study on tannin degradation within dyed woolen yarns. Molecules. 2019. https://doi.org/10.3390/molecules24122318.

\section{Publisher's Note}

Springer Nature remains neutral with regard to jurisdictional claims in published maps and institutional affiliations. 